This is an Accepted Manuscript of an article published by Taylor \& Francis Group in Development in Practice on 6/06/2012, available online:

http://www.tandfonline.com/doi/pdf/10.1080/09614524.2012.673556

Published details:

Crivello, Gina and Nardos Chuta (2012) 'Rethinking Orphanhood and Vulnerability in Ethiopia', Development in Practice 22 (4): 536-548. DOI:

10.1080/09614524.2012.673556

The article is reproduced in accordance with the self-archiving policies of Taylor \& Francis. 


\title{
Rethinking Orphanhood and Vulnerability in Ethiopia
}

\author{
Gina Crivello and Nardos Chuta
}

\begin{abstract}
'Orphans' became a category of vulnerable children deserving special protection in the context of the global AIDS epidemic, and currently the notion of 'Orphans and vulnerable children', or 'OVC', dominates much of the policy for protecting children across sub-Saharan Africa. Analysis of survey and qualitative data from Young Lives in Ethiopia found that parental death does not guarantee the often assumed negative impacts on children's experiences, and that inequalities between children are greater along dimensions of poverty and household location, compared to orphan status. 'OVC' obscures poverty as a main source of child vulnerability and is therefore an outdated approach.
\end{abstract}

[keywords: orphanhood, OVC, Ethiopia, child poverty, vulnerability]

\section{Introduction}

In recent decades, the image of the orphan has come to embody child vulnerability in sub-Saharan Africa. Estimates of the alarming numbers of children being orphaned by AIDS-related deaths in the region raised international concern about an 'orphan crisis' and the 'burden' of their care in already fragile family and community circumstances (Abebe and Aase 2007). In 2003, the publication of Africa's Orphaned Generation warned, 'With the number of children that require protection and support soaring - and ever-larger numbers of adults falling sick with HIV/AIDS - many extended family networks have simply been overwhelmed.' Thus, 'the children of Africa, orphaned by HIVIAIDS, are the world's responsibility' (UNICEF 2003: 6-7).

The care and protection of orphans features prominently in the agendas of key international agencies and donors seeking to improve child wellbeing globally; and they are behind the definitions, priorities and solutions guiding national plans to address child vulnerability. For example, one of the leading international agencies defined an orphan as a child who has lost one or both parents, and this technical definition has been adopted widely and at many levels for policy, programming and research worldwide (e.g., Children on the Brink 2002).

The attention given to orphans in the international child protection discourse suggests that orphanhood is a major, if not the major factor affecting child vulnerability in sub-Saharan Africa. An active research agenda focused on the risks associated with orphanhood has developed in tandem with a growing policy concern and programmatic focus targeting 'orphans and vulnerable children', or 'OVC', throughout the region. However, the very concept of OVC illustrates the tension that exists between targeting specific groups of children for support - such as orphans and developing strategies for addressing child vulnerability more generally. 
This article examines some of these challenges with reference to the case of Ethiopia where an OVC approach guides child protection. We used evidence from Young Lives $^{1}$, a long-term study of child poverty that has tracking two age cohorts of children, and their families, in Ethiopia since 2000. Survey analysis examined the degree to which child development outcomes were associated with orphan status, and other factors, such as household poverty. Analysis of qualitative data focused on children's own views and experiences of parental death within the context of their everyday lives. We situate our findings within the ongoing policy debates and conclude with a call to re-think the assumptions guiding OVC approaches in Ethiopia and, more broadly, the validity of imposing universal definitions on local experiences of child vulnerability.

\section{The global spotlight on orphans}

That orphans have emerged as a significant international child protection concern is illustrated by the results of a search of UNICEF's publications database covering the period 1996-2010 (www.unicef.org - accessed 17/07/2011). A search for publications tagged with 'orphan' resulted in 49 'hits' for the first five year period (2 publications in 1996), rising to 610 results in the year 2010. During this period, the orphan problem remained rooted in concerns about the impacts of HIV/AIDS.

At the height of the AIDS crisis, 'AIDS orphans' became a new category of 'vulnerable children' requiring special protection and attention' (Bray 2003:52), but the term eventually fell out of favour because it was potentially stigmatizing and failed to acknowledge that children could be negatively affected by AIDS regardless of orphan status. A joint report produced by UNICEF, UNAIDS and USAID explained, 'While not all orphaning is due to HIVIAIDS, orphaning remains the most visible, extensive, and measureable impact of AIDS on children.' (Children on the Brink, 2004: 4.) New terms like 'orphans and other children made vulnerable by HIVIAIDS' reflected these concerns, broadened beyond orphans, but remained AIDS-focused.

The alternative 'orphans and vulnerable children' (OVC) dropped reference to AIDS, and as an international framework gained in popularity and use in the early 2000 s. 'Orphans' are conspicuously the only named category of children, and despite disentangling itself in name from the AIDS epidemic, it remains strongly rooted in the global AIDS agenda. For example, in the most recent report on The State of the World's Children, the subject of orphans appeared in sections on the risks of HIV, national AIDS strategies, and reproductive health (UNICEF, 2011). On the websites of USAID and Save the Children USA, information on 'OVC' was accessed via sections on HIV/AIDS. ${ }^{2}$

The visibility of orphans in agency and donor agendas has been influential in shaping national plans of action for targeting child vulnerability throughout sub-Saharan Africa. For example, Ethiopia's first National Plan of Action on OVC (2004-2006) was developed as part of a Rapid Country Assessment, Analysis, and Action Planning (RAAAP) across 17 countries. ${ }^{3}$ However, the research base supporting such plans is flawed, lacking analytical clarity and consistency, including in basic definitions, such

\footnotetext{
${ }^{1}$ See www.younglives.org.uk for research design and methodology.

2 Accessed 20/07/2011 and 07/09/2011, respectively.

3 The exercise was created by USAID, UNICEF, UNAIDS, and The World Food Programme.
} 
as who is defined and counted as an 'orphan' (Bray 2003; Henderson 2006; Richter and Desmond 2008; Mientjes and Giese 2006; Sherr et al. 2008). This has led to contradictory findings regarding orphanhood as a source of child vulnerability.

The research and policy literature has also raised concerns about the ways in which orphans are conceptualized and how conceptualizations affect family and social cohesion, and the way young people see themselves (that is, through potentially exacerbating stigma or privilege) (Mientjes and Giese 2006; Sherr et al 2008). In some cases, the orphan label has become a privileged identity and a way to access aid from donors (Cheney 2010; Freidus 2010). Despite confused messages and unintended consequences, there is a substantial amount of international aid available for OVC support via HIV/AIDS funding; maintaining a focus on orphans may be an effective strategy for eliciting emotive responses and for mobilizing donor attention and funds (Meintjes and Geise 2006:416).

The case of the US Government is illustrative, beginning in 2003, when PEPFAR -the US President's Emergency Plan for AIDS Relief -- was launched to combat global HIV/AIDS. In 2008, nearly 5 billion dollars was earmarked over a five year period for 'orphans and vulnerable children', and in 2011, Ethiopia received funding for a new 100 million dollar programme to assist an estimated 500,000 orphans, vulnerable children and families every year over the next five years.

\section{OVC in Ethiopia}

The Ethiopian Ministry of Health recorded 2,656,195 single and double orphans in the country in 1987, and the numbers have increased to reach over 5 million children (under fifteen years old - EMOH 2007). Approximately 20 per cent of orphans are believed to have lost parents as a result of HIV/AIDS (UNAIDS 2008 and EMOH 2007). HIV/AIDS is a leading cause of orphanhood in Ethiopia, although the disease does not presently account for the majority of parents' deaths. In addition, there have been important episodic causes of orphanhood or separation of children from their parents, including famine, conflict and displacement (Cooper 2010:10). Orphanhood and parental absence are structural features of Ethiopian society (Abebe and Aase 2007:2059).

High rates of adult mortality in Ethiopia coincide with widespread poverty. Ethiopia is one of the world's poorest nations and in 2010 was ranked 157 out of 169 countries on the Human Development Index (UNDP). Ethiopia's Household Income and Consumption Expenditure survey (2004/5) identified 38.7 per cent of the country's population as poor with higher rates of poverty in rural areas where approximately 84 per cent of the population lives (Woldehanna et al 2011:17).

As in other countries across the region, Ethiopia adopted an OVC framework to guide action for vulnerable children, and there are currently plans to carry out a new 'situation analysis' of OVC across the country in order to inform a new National Plan of Action for OVC. A new National Plan of Action for Children is being developed simultaneously, this raising concerns amongst critics who question the need for separate plans and who point out that policy makers do not use existing research on OVC, so generating more data is unnecessary. 
PEPFAR funded development of the country's Standard Service Delivery Guidelines for Orphans and Vulnerable Children's Care and Support Programs (2010) which included definitions for OVC, defining an orphan as:

[A] child who is less than 18 years old and who has lost one or both parents, regardless of the cause of the loss. A vulnerable child is a child who is less than 18 years of age and whose survival, care, protection or development might have been jeopardized due to a particular condition, and who is found in a situation that precludes the fulfilment of his or her rights.

Whilst the guidelines go some way towards defining child vulnerability within the country, such definitions reflect international conceptualizations of childhood as defined chronologically below the age of 18 , and global notions of child vulnerability based on threats to individual children's rights and interpersonal abuses. Stronger links are therefore necessary between research, policy, and practice on the one hand, and, on the other, the contextual factors often lacking in such bureaucratic definitions. The question for this paper is: does the focus on orphanhood reflect the realities of Ethiopian children?

\section{Context of this research}

We analyzed data from Young Lives in Ethiopia: the third round of survey (2009) and a qualitative sub-study (2010) focusing on children's experiences of orphanhood and vulnerability. Sample households were poorer than average Ethiopian households but overall represented a wide range of poverty circumstances, albeit not nationally representative.

'Orphanhood' was not a criterion for recruiting study participants; nonetheless, we found that by the time they were aged 15, around 21 per cent of the older children had lost one or both parents, and among the younger group, aged 8, the figure was 10 per cent. Nationally, an estimated 18 per cent of Ethiopian households include at least one child who has lost one or both parents. At the time of the last survey (2009), the younger children in our sample were aged 7-8 $(n=1882)$ and the older children were aged 14-15 ( $n=973) .5 .8$ per cent of the younger children and 14 per cent of the older children were paternal orphans; reported maternal orphanhood was 2 and 4 per cent, respectively. Parental 'absence'4 was even more prevalent than parental death: 19 per cent of the younger cohort and 22 per cent of the older cohort were reported having missing fathers. Thus, paternal death was the most common form of parental death, and when a parent was reported absent, it was also more likely to be the father.

Participants in the qualitative sub-study were drawn from the existing Young Lives sample located in Addis Ababa and Hawassa cities. Data collection involved 63 individual interviews with 26 focus-children aged 9-16, caregivers, NGO and local government representatives, teachers, healthcare providers, and Iddir leaders (traditional burial association), and separate group discussions with children and caregivers. Prior to fieldwork, a policy context analysis involved 17 semi-structured

\footnotetext{
4 The survey asks how often the child sees his/her biological parents. 'Absence' here captures anything from 'sees weekly' to total absence.
} 
interviews with representatives from relevant NGOs, government and international organizations working in the area of OVC in Addis Ababa.

Qualitative fieldwork took place in Atkilt Tera (Addis Ababa) and Leku (Hawassa). Atkilt Tera is a hub for commerce and industrial activities, with a population of over 14,000 . It is regarded as the city's 'old quarter' and poverty is widespread. Street vending of fruits and vegetables, renting of houses for storage, and carrying goods for cash are key sources of income for residents. There are many problems in the locale related to housing conditions, sanitation and hygiene, infrastructure, economy, and societal risks.

Leku is an active quarter of Hawassa, the capital of the Southern Nations, Nationalities and Peoples Region (SNNPR), with roughly 23,000 inhabitants. Poverty is widespread and residents earn their living through petty trade, street vending, and daily labour. Common risks faced by children in the area included the presence of shisha houses (places where people go to smoke and chew chat, a mild stimulant leaf), bars, and brothels, and overcrowded living conditions.

\section{Survey results}

Our findings raise several questions about the relationship between orphanhood and vulnerability within the context of widespread poverty and rural/urban inequalities, both in terms of children's outcomes and their experiences. We begin by looking at the care of orphans in our sample, which is a major policy and programmatic concern in Ethiopia. Children who had experienced the death of one or both parents were more likely to be living in better-off households, this possibly reflecting a tendency for children to be taken in by family members who were financially better-off and the greater prevalence of parental death in urban settings. We found that despite considerable parental death and absence in our sample households, most children were reported to be living with relatives: only 2 per cent of the older cohort and 0.4 percent of the younger cohort were living with non-relatives.

Living arrangements differed depending on whether or not it was the mother or the father who had died or had been reported absent. There was a greater diversity of caregivers for children whose mothers had died or been reported absent. If the father had died or was absent, the caregiver was likely to be the biological mother (89 per cent younger cohort; 90 per cent older cohort). In mothers' absence, grandmothers tended to take on caring responsibilities. Care arrangements were also shaped by the age of the children, such that younger maternal orphans were more likely to be living with their fathers (43 per cent) when compared to older children whose mothers had died (22 per cent).

For children who had lost both parents, patterns of care also differed by age-cohort; younger children in this group were more likely to be cared for by a grandparent (64 per cent, compared to 20 per cent of older 'double' orphans); a much greater diversity of caregivers were reported for older 'double' orphans. Analysis of Ethiopia's Demographic Health Surveys of 2000 and 2005 reported similar trends, finding that 83 per cent of paternal orphans lived with their mothers, while 70 per cent of maternal lived with their fathers, and 51 per cent of double orphans lived with a grandparent (Beegle et al 2010). 


\section{Children's development outcomes}

A widespread policy and programming assumption has been that development outcomes for orphans are different relative to other children, and that orphans fare worse. We explored this assumption on a selection of survey variables relating to schooling and health outcomes. We found that younger orphans (single or double) were slightly more likely to be enrolled in school when compared to younger children whose parents were alive. This was in contrast to older orphans who were slightly less likely to be enrolled in school than other children their age. For both age groups, double orphans were more likely than any other group to be enrolled in school (96 per cent older double orphans, compared to 90.6 per cent non-orphans; 92.9 per cent younger double orphans, compared to 76.5 per cent non-orphans). We also found that for both age groups orphan status did not account for significant differences in reports of missing (a week of) school in the previous year.

There were, however, disparities in school enrolment amongst both age groups, depending on household location, favouring urban children. Similar disparities were evident in terms of household wealth, with children in better-off households more likely to be enrolled in school, for both age groups. The survey also found that in households reporting long-term illness children were more likely to have missed school (younger cohort 17.7 per cent; older cohort 14.8 per cent) compared to children in households without long-term illness (younger cohort 9.8 per cent; older cohort 11.6 per cent).

Information on body mass index (BMI) as an indicator of health for the older children found that overall 36 per cent of the cohort was below the healthy range. There were minor differences in BMI (older cohort) and height-for-age (younger cohort) in relation to orphan status. There were greater disparities based on where children lived, with children in rural households less likely to hit the healthy range. The wealth status of households was also associated with health outcomes such that children in poorer households were less likely to fall within the healthy range according to these measures.

The sample was then divided by orphan status, focusing on those households in the two poorest and two richest categories. Orphans living in better-off households fared better on health indicators compared to orphans in the poorest households. Results for the older cohort indicated that orphans in the poorest quintiles were doing better than non-orphans in the poorest quintiles (65 per cent and 55 per cent within the healthy range for $\mathrm{BMI}$, respectively). In the younger cohort, there were no differences between orphans and non-orphans in the poorest households.

The survey findings indicated that inequalities in schooling and health outcomes were larger along other dimensions of vulnerability, such as the location of children's households (rural or urban) and the material circumstances of their households. These trends are in line with findings from other studies comparing development outcomes for orphaned children relative to other children (Bray 2003; Campbell 2008; Richter and Desmond 2008). Children's outcomes, however, are not the same as their subjective experiences, and it is important to understand the ways in which young people experience and make sense of parental loss within the context of their everyday lives. 


\section{Children's experiences}

Daily life in Atkilt Tera and Leku is fraught with difficulties for both young and old. We analyzed children's experiences along three main axes: the first pertained to children's care relationships, the second to their social and material contexts, and the third related to the ways in which young people made sense of parental death.

Over half of the children involved in the qualitative study had experienced some form of parental death, and only two of the 25 children reported having both parents alive and living with them. In other cases, one or both parents were alive but living apart from the child, or perhaps nearby but not with the child due to housing shortage; some had migrated for work and a few had abandoned their children.

Children's care arrangements were therefore diverse, the majority of children lived with relatives, and even where parental death and absence were reported, many remained living with their mothers (father's death and absence being more prevalent).Regardless of who was the primary caregiver, the quality children's care and the security of their relationships were important factors shaping their experiences of orphanhood and vulnerability.

\section{Children's roles within the 'burden of their care'}

Given the fragility of many Ethiopian households, the role of the extended family and of community-based organizations has become a key question and OVC programmatic focus. Historically, in many African societies, the extended family played an important function in raising the young -- including when parents were living -- through short or long-term fostering, as a response to household crisis, as well as under favorable conditions (Abebe and Aase 2007; Abebe and Skovdal 2010; Kayongo-Male 1984). Amongst our sample households, family and other informal networks were crucial for support and survival. Household membership was fluid and many children resided with extended family. This was due to poverty and poor housing, parental migration for work, parental death or abandonment, and better opportunities for children (such as higher quality schooling).

A main policy concern has been the sustainability of this traditional form of protection and whether the numbers of orphans requiring homes has pushed families beyond their capacity (Abebe and Aase 2007). Such is the 'burden of orphan care' and the focus on protecting vulnerable children. Whilst acknowledging that all vulnerable children should be supported, it is important also to affirm the valuable ways in which young people contribute to the care networks of which they are a part. An examination of the experiences of orphanhood within the 'mutuality' of children's care relationships (Abebe and Skovdal 2010) shifts the focus away from what children lack (namely parents) and towards the resources they bring to bear on their situations.

For example, fifteen year-old Denbel was living with his mother and brother in Hawassa in extreme poverty. He had no place at home to study, and during the rainy season, the corrugated iron roof leaked and soiled his school notebooks. His mother earned money by trading firewood and Denbel combined daily wage labour with work in a local shop, managing both jobs alongside schooling. Denbel's father died when he was two years old, and the family's economic situation deteriorated. 'My mother 
always says that she doesn't have the capacity to fulfil all our needs. And I don't feel good because I don't have a father.' He got a job, explaining, 'When my family couldn't provide me with the necessities, I decided to work on my own and earn money to get what I need.' He gives his mother about a third of his earnings and uses the rest to cover his personal expenses.

Denbel believed that his family would not be struggling so, had his father been alive. But he accepted death as a natural and irrevocable occurrence, and did not think that he would suffer long-term effects. 'You know, we all are created to die. So, I don't have to remember him all my life since I myself will die one day.'

Denbel's case fits the sense of respect and obligation that structures children's roles and their responsibilities towards their households (Boyden 2009; Poluha 2004). Another example, of fifteen year-old Bereket, showed how children's work also contributed to a sense of pride and hope for the future. Bereket was being raised by his sixty year-old grandmother in Addis Ababa - along with three brothers and two cousins. After the school day ended, Bereket worked washing cars and changing tires, and he was proud of what he learned at work: 'I can manoeuvre some garage machines. I have a little driving skill, in addition to tire repair and maintenance.' He contrasted this to some of his friends, and said, 'I take risks to learn new things...I still have some friends who don't know how to drive because they don't take risks.'

Although Bereket and Denbel faced multiple layers of disadvantage, neither saw himself as a dependent victim. Their capacity to work and to earn money nurtured their sense of hope and contributed to their daily survival. Boys' and girls' experiences of orphanhood were therefore grounded within the context of their everyday roles, responsibilities and relationships. Being male was an important source of advantage for Denbel and Bereket in this respect, probably opening up opportunities for their apprenticeships and for mastering the skills and knowledge facilitating their adult roles later in life. Petty jobs like working in the fruit and vegetable markets, grocery stores or mechanic shops were often more accessible to boys, whilst girls' work clustered around or inside the home. Nonetheless, girls' contributions were also essential for mitigating household poverty and the effects of parental death, as part of mutual systems of care.

\section{Orphanhood and everyday risk}

A holistic view of orphanhood considers the wider social and material contexts of children's daily lives, including the pressing, everyday risks that shape childhood in these contexts. Crucial among these were the ways in which gender, age and household poverty interacted in shaping children's vulnerabilities. Whilst gender can be an advantage, it can also be a risk. Gender-based violence, such as rape and harassment, were common fears for teenage girls, and this influenced their livelihood opportunities and feelings of insecurity in the streets. Crowded living conditions were also common and brought together strangers renting accommodation under the same roof. This presented risks for girls and their moral standing, such as inappropriate or early sexual relations, often initiated through the exchange of favors and material goods. 
These were clear concerns for fifteen-year-old Fatuma's mother, in Addis Ababa. Fatuma's father died when she was very young and she had little memory of him. Fatuma worked a lot at home. She made injera (a traditional bread made of teffflour) to sell, especially when the mother became ill. Caregiver illness was common among households in our study, and frequently had economic repercussions related to diminished earning capacity and costs for treatment, on top of psychosocial impacts and anxieties about future uncertainty.

Fatuma's mother's life had been fraught with difficulties, even before becoming ill. She never attended school and when she went to work as a cleaner in a widow's home she was raped by one of the boarders. She became pregnant with a son who was subsequently raised by an aunt in the village. When she was pregnant with Fatuma, her husband, a different man, abandoned her, only to return five years later. Her mother remembered when Fatuma was born: 'I had nothing to cover her body with. So I used long sleeves of my clothes and made a trouser and a dress out of it.' Even now, she struggled to make ends meet as the money from washing clothes was not enough for the family.

Renting out space in their house was therefore crucial, but a significant source of worry for the mother. One boarder, a young day labourer, concerned her: 'The boy has a mobile phone and wants to lend it to Fatuma, but sometimes, both of them quarrel and I don't know the reason and she does not tell me either... I am not comfortable with the way the boy is approaching my daughter.' When asked about what she considered the main problems in her life, Fatuma made no mention of the young man, and instead pointed to her mother's illness and her fears of losing her. Nor did she emphasize poverty as a major obstacle: 'I don't think that poverty will be with me forever. So I am not worried about it... If I work hard, there is no reason why I should not fulfil my future goals the same as my friends and even reach a better position.'

Tsega's case is also elucidatory on this theme. She was fifteen years old and living with her mother and eight siblings in Hawassa. Tsega's father died when she was eleven, and following his death, her mother and older brother sought paid work, but her mother's job as a dishwasher and cook was frequently disrupted due to chronic illness.

The family's recent problems began when the father was crushed by a car while riding a bicycle, followed by two years of intense medical treatment; one of his legs became infected and he died. Prior to this, the family lived relatively comfortably; they owned their house, several horse drawn carts, and a hotel and butchery house. One by one these were sold to finance the father's treatment. Financial difficulties resulted in Tsega enrolling late in school and repeating grades. Echoing what many other children her age have said, and in spite of the difficulties facing the family, Tsega stated, 'As man is mortal, he [her father] died and so I have to accept.'

One of Tsega's biggest worries is being raped in her neighborhood. Her sister had been cheated by a boy promising marriage, but he abandoned her when she fell pregnant. Now that Tsega was a teenager, her mother feared that Tsega might also be cheated by a young man promising her things that she herself could not afford to provide for her daughter. 
Indeed, children's vulnerabilities were shaped by their household and community circumstances, rooted in poverty and exacerbated by parental illness and death, migration, family separation, and gender dynamics. Orphanhood within this context became one of many sources of vulnerability and not often the most pressing daily concern for boys and girls. Daily life was further shaped by intergenerational processes whereby long histories of parental disadvantage played out in children's current realities, providing, on the one hand, valuable lessons for the young, and on the other hand, another layer of hardship and risk to overcome.

\section{Making sense of orphanhood}

Many young people lacked detailed knowledge of their parents' passing, especially if they were young when their parents had died. It was also common for adults to shield children from painful information, so children's memories were often vague. These factors influenced their explanations and descriptions of parental loss, as did the quality of their current family relationships and household circumstances. In other words, where care and support were strong, children did not refer to parental death as a main factor shaping their current lives.

The case of fifteen year-old Genet in Addis Ababa is illustrative. She began living with her aunt following the death of her mother (when she was 5) and two years later her father, who had endured long periods of illness. In Genet's view, her aunt and uncle provided well for her, and theirs was amongst the better-off households in our sample. When asked about missing her parents she replied, 'I feel nothing because I don't know them very well...I feel a little sadness but not so much because I have missed nothing.' The material security and sense of nurturance experienced by Genet mediated her experiences of parental death.

This was not the case for fourteen-year-old Tagesu in Hawassa who explained much of her current difficulties with reference to her father's death. Her family history was redolent of gender-based violence. Tagesu's mother had married by abduction ${ }^{5}$ at the age of 15, and after giving birth to two children, she divorced. She later married Tagesu's father, but he died when Tagesu was three years old. When the mother migrated in search of work leaving behind Tagesu and her elder sister to work as day labourers, the sister was 'raped' by a man whom she later married and whose child she bore.

Tagesu believed that her father's death plunged the family into deep poverty and deprived her of his love and protection. Many of her needs remained unmet, and she felt that had her father been alive he would have educated her in a private school and given her plenty of food. 'It is the hunger and lack of food that I cannot handle. I tell my mother when I am hungry. If she has something, she gives it to me, and if she does not have anything she weeps with me.' In contrast to Genet's account, Tagesu and her family contended with multiple layers of disadvantage and the nature of risk

5 'Abduction' is a type of marriage practiced in rural areas when the boy is poor (thus, avoiding payment of bridewealth) or when the girl refuses to accept a marriage proposal. 
for their household was cumulative and compounding, this influencing the meaning Tagesu gave to her father's death.

Many of the older children expressed sadness regarding parental loss, but their views also demonstrated a degree of fatalism which may have aided their coping over time. They considered parental death as inevitable and natural. For many of them, like Tagesu, daily life entailed confronting a constellation of risks within and outside of the household. Poverty was fundamental in shaping the way they experienced a variety of shocks, including parental death, absence, abandonment and illness. Their struggles and successes were lived out within the context of mutual care systems wherein children's contributions were often essential for household survival. Under these circumstances, the extended family and community comprised a major resource for children, particularly in the absence of external support, and their positive relationships with caregivers were protective in mediating their experiences. In the absence of a strong web of care and material support, parental death provided children with the explanation that gave meaning to their daily struggles.

\section{Conclusion}

The notion of 'OVC' - 'orphans and vulnerable children' - represents a positive move towards recognition that orphaning is not the sole source of risk for children in subSaharan Africa, where the label has most consistently been applied. Orphans within the context of the AIDS epidemic have, nonetheless, retained a prominent place in OVC discourse at many levels - from international agency and donor agendas, through national-level OVC action plans, down to programmes; and in some contexts, the OVC identity has become a new social category and personal identity. Thus, OVC is not simply an innocuous bureaucratic label created to measure parental death and child vulnerability across diverse contexts; it also functions to shape thinking about who are the world's vulnerable children and to funnel global funds to support them.

In Ethiopia, the term OVC is widely used by Government and other stakeholders, including development practitioners and to date, the category has not been widely questioned. However, increasing research evidence indicates a frequent mismatch between externally generated bureaucratic categories such as 'orphan' and 'OVC' and locally-derived understanding of parental loss, family, childhood, or vulnerability. As happened to the categories that came before it, cracks in the OVC framework are beginning to show at international level. ${ }^{6}$

Researchers and policymakers in Ethiopia must therefore decide whether their efforts will become more targeted or universalized. That the Ethiopian government is simultaneously developing separate plans of action for OVC and for the country's general child population epitomizes this dilemma. In line with other studies, we our research findings from Ethiopia suggest that a focus on orphans obscures the vulnerabilities of other groups of children. We presented survey analysis indicating that inequalities in schooling and health outcomes were larger along other dimensions of vulnerability, such as the location of children's households and the

\footnotetext{
${ }^{6}$ See the 2010 report to the US Congress on the Public Law 109-95 (The Assistance for Orphans and Other Vulnerable Children in Developing Countries Act of 2005) which shifted focus away from 'OVC' and towards 'highly vulnerable children'.
} 
material circumstances of their households, when compared to analysis by orphan status. Vulnerability was related to living in the context of acute poverty, so childhood poverty and associated risks need to be tackled, rather than specifically targeting orphans as a policy/programmatic priority. Qualitative analysis also found that orphanhood does not guarantee negative impacts on children's experiences and development outcomes, and many of the problems faced by orphans are also faced by other disadvantaged children in their communities. Indeed, many of the types of aid provided to orphaned children target their poverty ( food, school materials, and clothing); it is therefore important to address universal access to basic supports for children, such as through social protection programmes.

Rethinking orphanhood and vulnerability also requires improved understanding of risk factors for children, and further research is needed on the interaction and accumulation of risks for children, on the mediating factors that decrease or enhance child vulnerability, and on the importance of contextual factors. In this study, several factors were shown to influence young people's experiences of parental death and the quality of children's care relationships and their material security were crucial among these. However, poverty and gender-based violence were among the more pressing everyday risks for many children. The meanings and experiences of childhood, family, vulnerability, and orphanhood are highly contextual, so greater attention to the social dimensions of child vulnerability is needed. In this respect, policy for protecting children in Ethiopia must also acknowledge the resources that young people bring to bear on their household circumstances through their agency, roles and responsibilities. OVC diverts attention away from the crushing poverty that is the backdrop for many childhoods in Ethiopia. Tackling childhood poverty needs to be at the heart of strategies to address the needs of all vulnerable children currently growing up in the country.

\section{Acknowledgements}

We are grateful to the children, families and others who collaborate with Young Lives. Yisak Tafere led the fieldwork and reporting for this study. Elizabeth Cooper, Marlijn Lelieveld, Claudia Seymour and Laura Valadez provided excellent research consultancy. Helen Murray reviewed an earlier draft of the paper. Young Lives is core-funded from 2001 to 2017 by the UK Department for International Development (DFID), and co-funded by the Netherlands Ministry of Foreign Affairs from 2010 to 2014. Bernard van Leer Foundation and the Oak Foundation fund sub-studies.

\section{References}

Abebe, T. and Aase, A. (2007) Children, AIDS and the politics of orphan care in Ethiopia: The extended family revisited. Social Science and Medicine 64: 20582069.

Abebe, T. and Skovdal, M. (2010) Livelihoods, care and the familial relations of orphans in eastern Africa. AIDS Care 22(5): 570-576.

Beegle, K., Filmer, D., Stokes, A. and Tiererova, L. (2010) Orphanhood and the Living Arrangements of Children in Sub-Saharan Africa. World Development 38(12): 1727-1746. 
Boyden, J. (2009) Risk and Capability in the Context of Adversity: Children's Contributions to Household Livelihoods in Ethiopia Children, Youth and Environments 19(2): 111-137.

Bray, R. (2003) Predicting the social consequences of orphanhood in South Africa. African Journal of AIDS Research 2(1): 39-55.

Cheney, K. (2010) Expanding vulnerability, dwindling resources: Implications for orphaned futures in Uganda. Childhood in Africa, 2(1): 8-15.

Cooper, E. (2010) 'Orphans and Vulnerable Children' and Risk in Ethiopia: A Review of Research Findings, unpublished report. Young Lives.

Ethiopian Federal Ministry of Health/National HIV and AIDS Prevention Control Office (2007) AIDS in Ethiopia, 6 $6^{\text {th }}$ Report. Addis Ababa: Ethiopian Ministry of Health. http://www.etharc.org/AIDSinEth/publications/AIDSinEth6th en.pdf

Ethiopian Federal Ministry of Women's Affairs (2010) Standard Service Delivery Guidelines for orphans and vulnerable children's care and support programs. Addis Ababa: Ethiopian Ministry of Women's Affairs. http://hivaidsclearinghouse.unesco.org/search/resources/iiep ethiopia ovc guideline s 2010.pdf

Campbell, P., Handa, S., Moroni, M., Odongo, S., and Palermo, T. (2008) Assessing the 'orphan effect' in determining development outcomes for children in 11 Eastern and Southern African countries. Nairobi, Kenya: UNICEF.

Freidus, A. (2010) Raising Malawi's Children: Unanticipated Outcomes Associated with Institutionalised Care. Children \& Society 24: 293-303.

Henderson, P.C. (2006) South African AIDS Orphans: Examining assumptions around vulnerability from the perspective of rural children and youth. Childhood 13(3): 303-327.

Kayongo-Male, D. (1984). The sociology of the African family. New York: Longman.

Meintjes, H. and Giese, S. (2006) Spinning the epidemic: the making of mythologies of orphanhood in the context of AIDS. Childhood 13(3): 407-430.

Poluha, E. (2004) The Power of Continuity: Ethiopia through the Eyes of its Children. Uppsala: Nordiska Afrikainstitutet.

Richter, L. and Desmond, C. (2008) Targeting AIDS orphans and child-headed households? A perspective from national surveys in South Africa, 1995-2005, AIDS Care 20(90) 1019-1028.

Sherr, L., Varrall, R., Mueller, J., Richter, L., Wakhweya, A., Adato, M., Belsey, M., Chandan, U., Drimie, S., Haour-Knipe, V., Hosegood, M., Kimou, J., Madhavan, S., Mathambo, V., and Desmond, C. (2008) A Systematic review on the meaning of the 
concept 'AIDS orphan': confusion over definitions and implications for care, AIDS Care, 20 (5) 527-536.

UNAIDS (2008) Epidemiological Fact Sheet on HIV and AIDS, 2008. http://www.unaids.org/en/CountryResponses/Countries/ethiopia.asp

UNAIDS, UNICEF, and USAID (2002) Children on the Brink 2002: A joint report on orphan estimates and program strategies. Washington, DC: UNAIDS, UNICEF, and USAID.

UNICEF (2003) Africa's Orphaned Generation. New York: UNICEF.

UNICEF (2011) The State of the world's children. New York: UNICEF.

UNICEF, UNAIDS, USAID, 2004. Children on the Brink 2004: A joint report on new orphan estimates and a framework for action, Washington DC, July.

Woldehanna, T., Gudisa, R., Denbel, Y., and Pankhurst, A. (2011) Young Lives: Ethiopia Round 3 Survey Report 2009, Oxford: Young Lives 